\title{
Developing a Web-based system by integrating VGI and SDI for real estate management and marketing
}

\author{
J. Salajegheh a *, F. Hakimpour ${ }^{\mathrm{b}}$, A. Esmaeily ${ }^{\mathrm{c}}$ \\ ${ }^{a}$ GIS Engineering, Graduate University of Advanced Technology, Iran-sjavad24@yahoo.com \\ ${ }^{\mathrm{b}}$ Assistant Professor, Department of Surveying and Geomatics Engineering, University of Tehran, Iran-fhakimpour@ut.ac.ir \\ ${ }^{c}$ Department of RS Engineering, Graduate University of Advanced Technology, Kerman, Iran- aliesmaeily@ hotmail.com
}

KEY WORDS: real estate support system, VGI, SDI, Web2.0 Broker (W2B), Service composition

\begin{abstract}
:
Property importance of various aspects, especially the impact on various sectors of the economy and the country's macroeconomic is clear. Because of the real, multi-dimensional and heterogeneous nature of housing as a commodity, the lack of an integrated system includes comprehensive information of property, the lack of awareness of some actors in this field about comprehensive information about property and the lack of clear and comprehensive rules and regulations for the trading and pricing, several problems arise for the people involved in this field. In this research implementation of a crowd-sourced Web-based real estate support system is desired. Creating a Spatial Data Infrastructure (SDI) in this system for collecting, updating and integrating all official data about property is also desired in this study. In this system a Web2.0 broker and technologies such as Web services and service composition has been used. This work aims to provide comprehensive and diverse information about property from different sources. For this purpose five-level real estate support system architecture is used. PostgreSql DBMS is used to implement the desired system. Geoserver software is also used as map server and reference implementation of OGC (Open Geospatial Consortium) standards. And Apache server is used to run web pages and user interfaces. Integration introduced methods and technologies provide a proper environment for various users to use the system and share their information. This goal is only achieved by cooperation between all involved organizations in real estate with implementation their required infrastructures in interoperability Web services format.
\end{abstract}

\section{Introduction}

Importance of real estate, because of deep and significant impact on the macroeconomic in the area of trading, sales and pricing in all countries specially our country Iran is a fact. Importance of real estate in various aspects and huge investments and numerous profits that may be gained in this area, have created strong incentives to enter this market for different individuals and groups. These incentives may also provide a setting for abuse and illicit gains. Several factors play role in this field that the most important are the lack of awareness of some of the activists in real estate about the property information and the absence of clear and comprehensive rules and regulations for the trading and pricing of property. Property information is now completely scattered in different organizations including property registration offices, cadastre office and municipal offices. Due to the lack of integrated and comprehensive information, transactions and pricing methods most commonly don't have a clear and scientific trend. Therefore this deficiency creates many problems for the people involved in this field. Some of problems can be local and bubble growth for prices without noting specific basis.

This study has tried to introduce and implement a real estate support system that can largely resolve expressed problems. This system uses a variety of technologies and methods including crowd-sourced environments, Spatial Data Infrastructures (SDIs), Web services, Web GIS, Service composition and Web2.0 Broker (W2B). Then these technologies and methods will be briefly introduced and their relation to the subject of research and the role and impact of them in solving expressed problems will be discussed. In the next step the proposed architecture of research for real estate support system and various parts of it will be explained. Finally the implementation of desired real estate support system will be briefly described.

\section{1 crowd-sourced environments}

With the advent of Web2.0 and the opportunity to share the information by users, Web-based crowd-sourced environments expanded greatly.

In recent years the use of information collected from crowdsourced environments is known as a valuable source of spatial information. (Goodchild, 2007) titled this gathered information from crowd-sourced environments as voluntary geospatial information (VGI). One of the fields using this information is property. Information relating to property is shared by different users in a wide variety of purposes such as marketing and trading.

Despite numerous shortcomings and problems that exist in the data collected from these environments, we can apply some methods to retrieve appropriate and reliable information about the property from which and use for further applications.

\subsection{Spatial Data Infrastructures (SDIs)}

Spatial Data Infrastructures (SDIs) refer to a set of fundamental spatial technologies, policies and standards that improves access and utilization of spatial data. One of SDI tasks is helping to spatially empower groups and the states by providing the policies (Rajabifard, 2008). It has distinctly been revealed, especially in the last ten years that spatial data requirements of today's applications or projects could be met only through an effective cooperation between different institutions or parties. One of these applications is real estate. By implementation an SDI for real estate we can access large amount of spatial data. 
This goal can be achieved through interoperability cooperation between different organizations associated with the property.

\subsection{Concept of service-oriented Architecture (SOA) and Web services}

SDIs provide access to spatial data and operations through interoperability, particularly Web services. These gathered spatial data and operations can be linked to establish specific location-based business processes that can support a variety of applications.

SOA Architecture is shown in figure 1. Nowadays SDI is known with SOA architecture that uses Web-services as the most common procedures. W3C (2004) defines a Web-service as a software system designed to support machine to machine interactive function on the network.

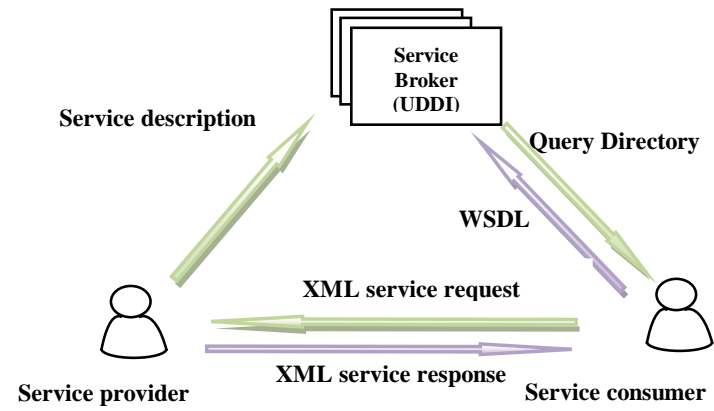

Figure 1. SOA Architecture (Fang, 2009)

As previously noted, much of the information about the property is distributed in different organizations. This research proposes that to integrate the data in an SDI infrastructure, each of these organizations should provide its own required Web services and share their information in a common format and language.

\subsection{WEB GIS}

Web GIS is a new development of GIS that extends its applications. (Mansourian et al, 2006) described Web GIS system based on the following five components:

1. User Interface: For users to access and analyze data

2. Web Server and software server: To get the user request and send it to a map server
3. Map Server: For data analysis and query based on user requests

4. Data Server: To retrieve data from a database to support the map server

5. Database: Managing spatial and attribute data By using SDI as a framework and a set of Web-based tools

Real estate management can be easy by providing a better way to collect, access, use and manage spatial data. In this context a Web-based GIS with an SDI as a framework can be a useful tool for facilitating property management because of the need for interaction between buyers, sellers, real estate transactions agencies, decision makers and planners.

\subsection{Service Chaining or Service Composition concept}

Very often a single service is insufficient to complete a task and a combination of services is required. Service composition is a way to develop applications in SOA. In service composition definition terms like service chaining and association of services is used (Alameh, 2003).

In this research service composition or service chaining technique is used to create connections between multiple services about real estate and the original system to support desired business processes.

\subsection{WEB2.0 Broking method (W2B)}

Web2.0 broker is a tool to facilitate access and retrieve data from various Web2.0 services. This broker allows users to connect multiple services that make possible retrieving data to

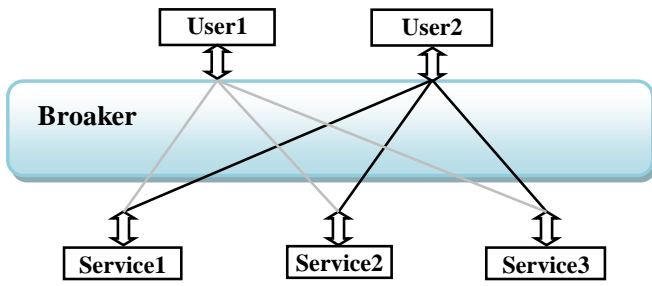

Figure 2. Broking method concept in web (Diaz,

access from a wide variety of applications published with Web2.0 services. (Diaz, 2012)

Web 2.0 simplicity enables users to generate and share information through one-click services.

\begin{tabular}{|c|c|c|}
\hline \multirow{3}{*}{ User Level } & \multirow{9}{*}{ 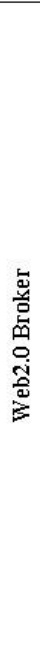 } & Buyers- Sellers- real estate agencies- Researchers- Government- Academics \\
\hline & & WEB browser \\
\hline & & $\begin{array}{l}\text { Openlayers map, Google Earth plug-in } \\
\text { Google Map plug-in, GIS analyses }\end{array}$ \\
\hline \multirow{2}{*}{$\begin{array}{l}\text { Server } \\
\text { Level }\end{array}$} & & PostgreSql/PostGIS server \\
\hline & & $\begin{array}{lccc}\text { Spatial query, Overlay } & \text { run OGC standards, } & \text { running html, PHP, } \\
\text { Distance calculation, buffer , } \ldots & \text { displaying map, zoom, pan, } \ldots & & \text { Java script }\end{array}$ \\
\hline $\begin{array}{l}\text { Service } \\
\text { Level }\end{array}$ & & $\begin{array}{l}\text { Property query service- Similar property find service- DBMS service- Cadastre office wfs } \\
\text { service- Registery office wcs service- Municipal office wfs service- Natural resources office wfs } \\
\text { service- Housing and urban office wfs service- Cultural heritage office wfs service }\end{array}$ \\
\hline Data Level & & $\begin{array}{c}\text { Services database: Cadastre office, Registration office, Municipal office, Natural resources } \\
\text { office, Housing and urban office, Cultural heritage office } \\
\text { VGI database: Data collected from users(buyers, sellers, real estate agencies) } \\
\text { Available VGI sites database: Data collected from VGI sites for real estate market such as: } \\
\text { www.moshaver.com, whw.iranestate.com, ... } \\
\text { Spatial database: includes geometry of estates, learning places, shopping places, streets, health } \\
\text { centers, religious centers, industrial and workshop centers with their attribute information }\end{array}$ \\
\hline Model & & Model Library \\
\hline Level & & Dlls, JavaScript codes, CSS, Includes \\
\hline
\end{tabular}

figure 3. Proposed real estate support system architecture 


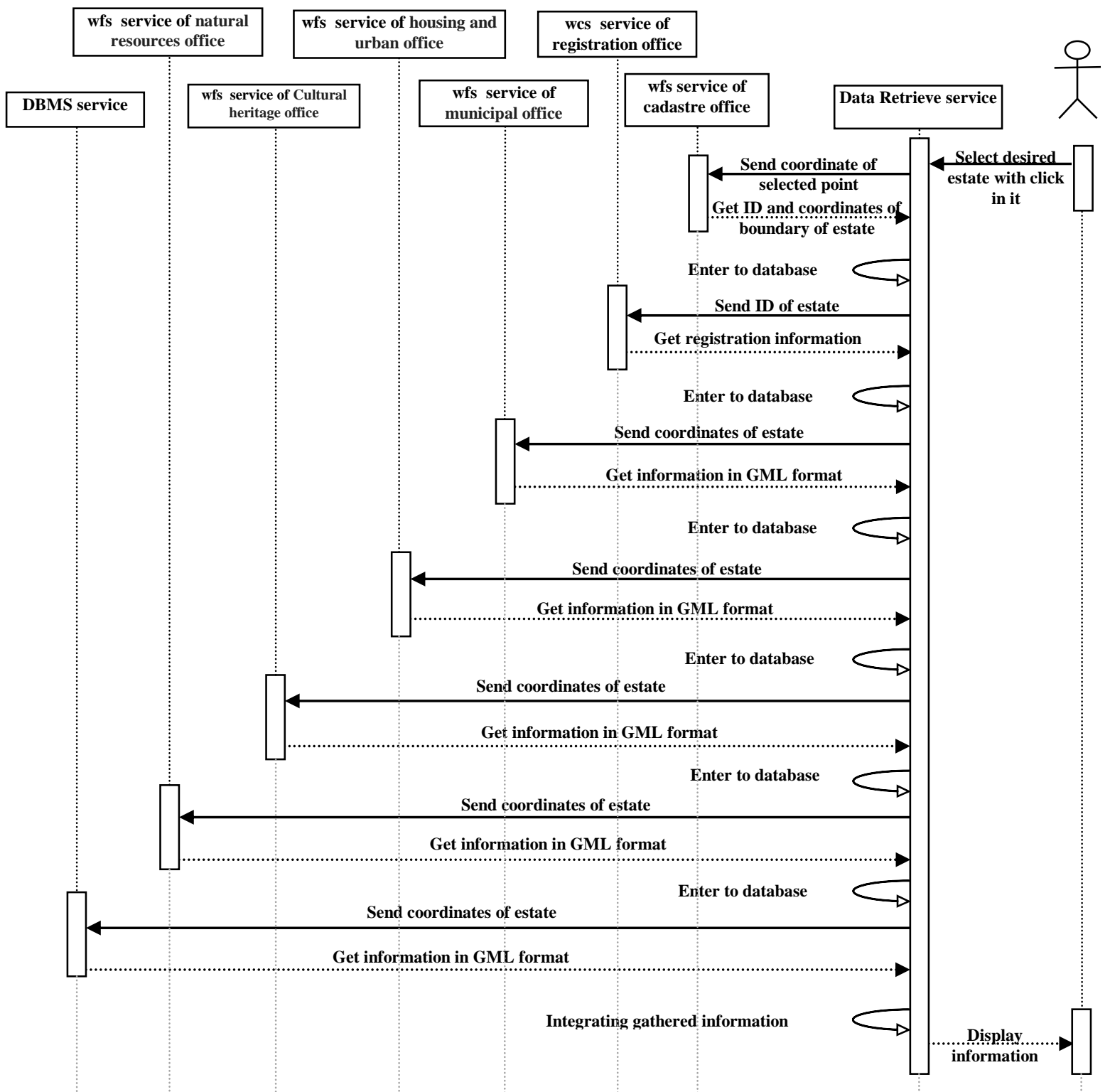

Figure 4. UML sequence diagram for data retrieving service

Development W2B service considering the interaction of official (SDI) and non-official (VGI) data enables us to integrated search and retrieve datasets from both sets of data about (figure 2). Integration and interaction of user-generated contents (U.G.C.) with official spatial data sets make the best environment to make decisions in many real-world issues such as real estate.

In this research we try to present a model and guidelines by which implementation of crowd-sourced application systems about real estate information services through a Web2.0 broker (W2B) is desired. The system can retrieve any information about the property from the various information services to assist the users. This information is a compilation of information collected from various Web crowd-sourcing environments for marketing and real estate exchanges and information collected from services of various organizations.

\section{The proposed real estate support system}

Proposed real estate support system architecture in this paper as shown in figure 3 is composed of five levels that are: user, server, service, data and model that will be discussed in more details. All these levels are connected through the W2B middleware layer. This structure creates an integrated and centralized real estate support system in order to enable integrated search and optimized retrieval datasets from both official and non-official data. Sequence diagram of data retrieving service based on service chaining technique is shown in figure 4. This chart offers a summary of the functionality of information retrieval services for data collection from a variety of services related to real estate. This information is given descriptive terms such as registration information and also in spatial form such as placing on the road widening plan that is received in GML format. Finally, all the gathered information has provided user in writing or displayed on map.

\subsection{User Level}

User level includes system users and constituents of the interface. Users of the system consist of several groups such as buyers, sellers, real estate agencies, government, academics and researchers. These target users use those parts of system that depend on the scenario considered each of them in.

Users apply the system and share their information with different objectives. In this context, there are restrictions. For example sharing spatial information by real estate agencies is a 


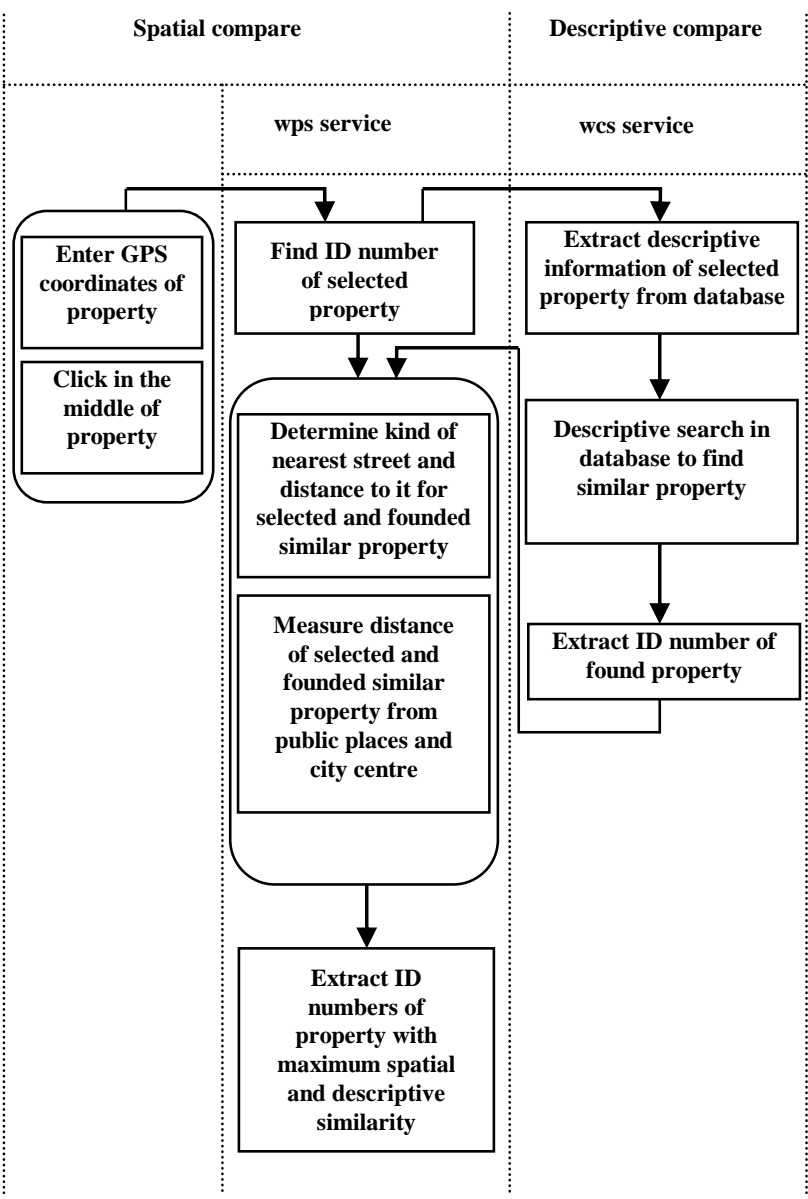

figure 5 . The process of similar property find service

controversial issue. But if the security of the system and interests of transactions is supplied these limitations can be overcome to a considerable extent.

The user interface consists of Web pages, including map pages, query pages, data entry pages and display of information. To increase the efficiency and quality of the system as well as assisting the user the plug-ins available including Google Earth plug-in, Google Map plug-ins used in the system and to enhance capabilities of map to appropriate spatially display to user Openlayers framework is used for writing desired applications in JavaScript.

\subsection{Server Level}

The server level consists of three components that are: PostgreSq1/PostGIS server, Geoserver and Apache server. PostgreSq1/PostGIS server is employed to perform a variety of spatial and non-spatial analysis required by the system including overlay, distance measurement, spatial query, retrieval and interpolation of data from the database. Geoserver is the reference implementation of Open Geospatial Consortium (OGC) standards. More capabilities and facilities can be added with JavaScript programming in OpenLayers to adjust displaying map, thickness and colour of lines and other visual features of the map. Finally Apache server is put into operation to provide HTML pages and JavaScript codes, run PHP codes and connect to the database and map server. This server is responsible for the connection between Web pages and PostgreSq1/PostGIS server and Geoserver. This component in close collaboration with User level is involved in preparation and implementation of user interfaces.

\subsection{Service Level}

Services designed for real estate support system are divided into two general categories: internal and external or organizational services.

Internal services consist of three below services:

- Property query service: this service searches for property interest for the user based on the user preferences.

- Similar property find service: this service finds similar property with the property selected by the user based on the maximum spatial and descriptive proximity to help a suitable selection.

- DBMS service: this service retrieves data of selected property from the database and displays it to the user to help a suitable selection.

For example the process of similar property find service is shown in figure 5.

This service is a combination of wcs and wps services of real estate support system. At first with the selection of desired property by the user the selected coordinates of the property enter to wps service. Wps service extracts the ID of property and sends it to wcs service. By using the two wps and wcs services descriptive and spatial information of the property is obtained. Finally with descriptive and spatial compares the similar properties are extracted from the database that can be used in future applications.

And external or organizational services are: Cadastre office wfs service, registration office wcs service, municipal office wfs service, natural resources office wfs service, housing and urban office wfs service and cultural heritage office wfs service.

The use of external or organizational services has been proposed as one of the suggestions of this research. But at present the relevant organizations haven't provided their required infrastructures. If these infrastructures implemented, the proposed methods and models can be implemented and have its maximum performance.

\subsection{Data Level}

Data level includes all types of data collected from multiple sources in the system and gathered in the form of an integrated database which is made up of several different databases. These databases include organizational services database, VGI database, available VGI sites database about real estate

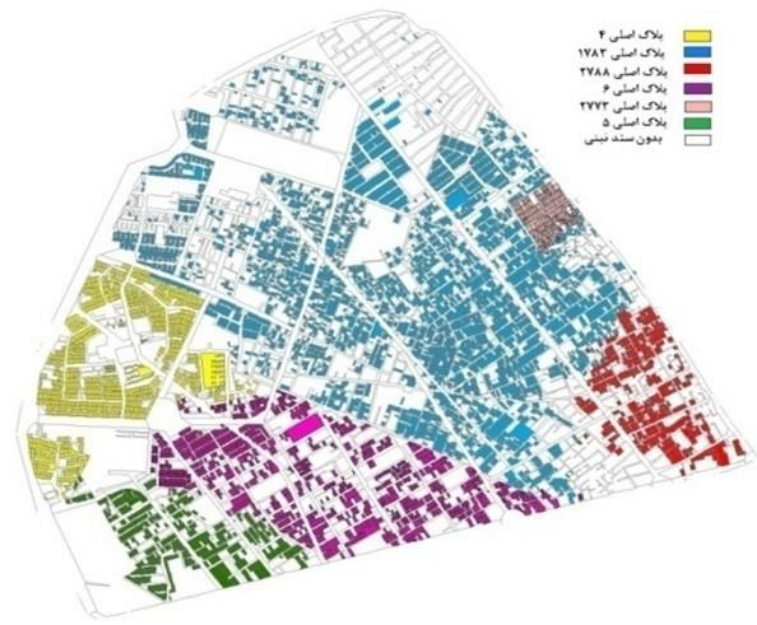

figure 6 .Map of registration ranges from study area 


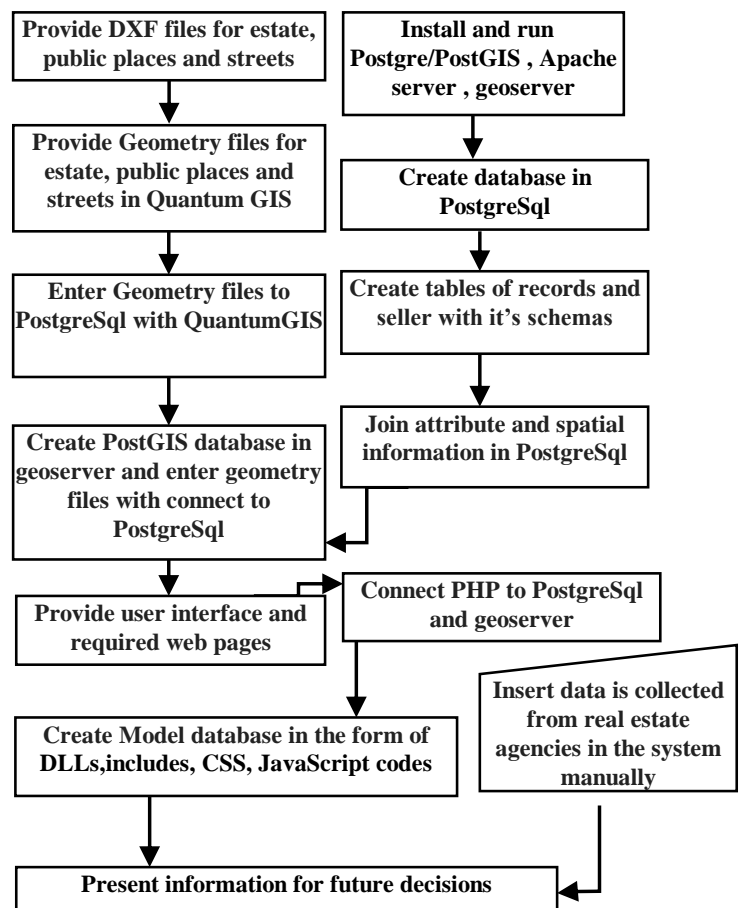

figure 7. Overall process of real estate support system

exchanges and spatial database.

The organizational services database includes information gathered from cadastre office, registration office, municipal office, natural resources, housing and urban office and cultural heritage office services. This information is received and collected over time and when users refer to the system, the data is weighted depending on the time of collection and used for future applications. VGI database contains information gathered from various users of the system with a variety of purposes, including marketing and advertising. This information may be used in applications depending on the type, quality and time of publish. Available VGI sites database for real estate management and marketing can also be considered as a good resource to strength the integrated database. Spatial database includes spatial data of educational places, shopping locations, streets, health centres, religious centres, industrial and workshop centres with their attribute information. This information is entered to the system first at the time of design and implementation of system. All of these databases can act as a complementary of each other and can be integrated into a comprehensive database for real estate management and marketing and provide more accurate and reliable data retrieval. This research uses a part of cadastre office database that by help of which registry zones is identified. Map of these zones from the study area is shown in figure 6 . It should be noted here that the study area of this research is a part of civil zone of Kerman (Iran). The spatial database from public places and streets is also used. Awareness of the quality and quantity of access to public places such as educational and religious buildings, shopping centres and health centres and also the name and quality of the various streets can have an effective role in real estate transactions and pricing. Access to other databases such as registration office, municipal office, natural resources office, housing and urban office and cultural heritage office can help to complete information and play a complementary role in determining the effect of various local utility on real estate valuation.

It should be noted that the accuracy of the data collected from various sources was not concerned in this study. Also it is

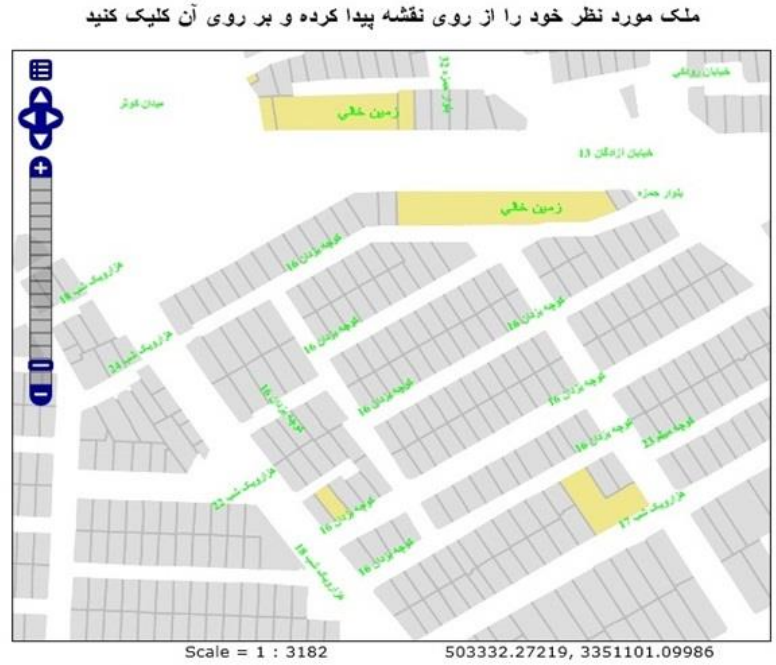

figure 8. Screenshot of map page from designed system

assumed that the information entered in the system is free of any damaging information.

\subsection{Model Level}

Model level includes all designed models by the system in different formats and programming languages such as JavaScript codes, DLL, CSS and includes. These models are gathered in a library named model library and also called by the Web2.0 broker service when needed and returns desired output. The overall process of real estate support system implementation is shown in figure 7. As previously noted, this system is implemented and run in a crowd-sourcing environment based on direct interaction with users. User interface pages contain map and information display user interface are illustrated in figure 8 and figure 9.

User can find the desired property by many methods on the map that are:

- $\quad$ Find property by entering approximate address

- $\quad$ Find property by GPS coordinates

- Find property by searching on the map page

Then the user can go to display information page by clicking in the middle of property. This page consists of two parts. All information from the selected property is displayed in the first part that includes information collected from organizational services (SDI) and information entered by other users (VGI).
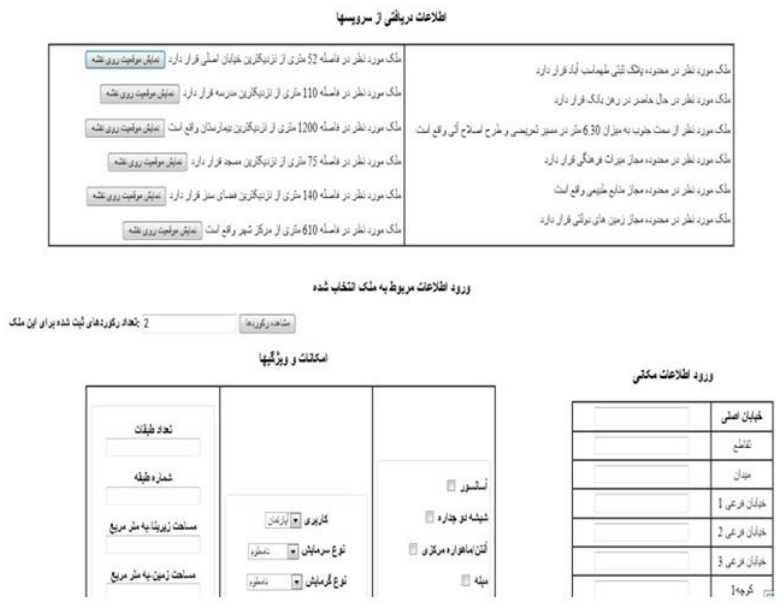

figure 9. Screenshot of display and entry information user interface page 
Displaying this information and user's awareness of it is a significant contribution to the users for future decisions. The second part is related to enter spatial and descriptive information of desired property by the user. After filling the form by the user information is stored in the database and may be used for further usages.

\section{Conclusions}

In this paper the role of voluntary geographic information (VGI) and Spatial Data Infrastructure (SDI) in collect, retrieve, analyze and share information about real estate for use by various users including buyers, sellers, real estate agencies, government and academics was studied. Then some of applied technologies and infrastructures with some models used in recent years were applied. Implementation the proposed real estate support system five-level architecture in a crowd-sourced environment is a proper method for various real estate users to easily access to all information about property gathered from different sources. Combination and modulation of VGI and SDI with use of techniques like service composition provide large volume of reliable information for various users. This information assist to manage, advertise and make decision despite of differences and inconsistencies can be in formats and preparation methods and display information. Integrating this information and display it to the users prevents largely individual opinions interfering in real estate trading and pricing. Also local utility values and their impact on trade and pricing indices get more logical process and clear direction.

\section{REFERENCES}

Alameh, N., 2003. Chaining geographic information Web services. IEEE InternetComputing 7 (5), 22-29.

Akıncı, H., Sesli, F., Dogan, S., 2012.Implementation of a Web services-based SDI to control and manageprivateownership rights on coastal areas, Ocean \& Coastal Management: PP. 5462 .

Bejar, R., Latre, M., Lopez, F., Nogueras ,J., Zarazaga, F.J., Muro, P., 2012. SDI-based business processes: A territorial analysis Web information system in Spain, Computers \& Geosciences 46, PP. 66-72.

Celliers, L., Longhorn, R., 2007. African Requirements and Responses, 8th International Symposium on GIS and Computer Mapping for Coastal Zone Management, Coastal Spatial Data Infrastructure (CSDI) (CoastGIS 2007), October 8-10, Santander, Spain.

Comert, C., Ulutas, , D., Akıncı, H., Kara, G., 2010. Semantic Web services forimplementingnational spatial data infrastructures. Scientific Research and Essays 5(7), 685-692.

Cui, Y., 2013. A systematic approach to evaluate and validate the spatial accuracy of farmers market locations using multigeocoding services, Applied Geography 41, pp. 87-95.

Davies, J., 2003. Expanding Spatial Data Infrastructure model to support spatial wireless applications, Ph.D. Dissertation, Department of Geomatics, The University of Melbourne, Melbourne, Australia, 210 pp.

Diaz, L., Granell, C., Huerta, J., Gould, M., 2012. Web 2.0 Broker : A standards-based service for spatio-temporal search of crowd-sourced information, Applied Geography 35, PP. 448459.

Fang, Y., Lin, L., Huang, C., Chou, T., 2009.An integrated information system for real estate agency-based on serviceoriented architecture, Expert Systems with Applications 36, PP. 11039-11044.

Goodchild, M.F., 2007. Citizens as sensors: the world of volunteered geography.Geojournal 69, 211-221.

Georgiadou, Y.,Stoter, J., 2008. SDIforpublicgovernanceimplicationsforevalua- tionresearch.

Goodchild, M. F., 2008. Assertion and authority: the science of user-generated geographic content, In Proceedings of the colloquium for Andrew U Frank's $60^{\text {th }}$ birthday, GeoInfo 39, Department of Geoinformation and Cartography, Vienna University of Technology.

Goodchild, M. F., \& Glennon, J. A., 2010. Crowdsourcing geographicinformation fordisaster response: a research frontier, International Journal ofDigital Earth, 3(3),PP. 231-241.

Han, W., Di, L., Zhao, P., Wei, Y., Li, X., 2008. Design and implementation of GeoBrain online analysis system (GeOnAS). In: Bertolotto, M., Ray, C., Li, X. (Eds.), W2GIS 2008. Lecture Notes in Computer Science, vol. 5373. Springer- Verlag, Berlin, Heidelberg, pp. 27-36.

Latre, M.A. , Lo pez-Pellicer, F.J., Nogueras-Iso, J., Bejar, R., Muro-Medrano, P.R., 2010. Facilitating e-government services through SDIs: an application for water abstractions authorizations.

Mansourian, A., Rajabifard, A., Valadan Zoej, M.J., Williamson, I., 2006. Using SDI and Web-based system to facilitate disaster management, Computers \& Geosciences 32, PP. 303-315.

Munro, R., 2012. Crowdsourcing and the crisis-affected community: Lessonslearnedand looking forward from mission 4636. Information Retrieval.http://dx.doi.org/10.1007/s10791012-9203-2.

Rajabifard, A.., 2008. A spatial data infrastructure for a spatially enabled govern- ment and society.

Salvati, P., Balducci, V., Bianchi, C., Guzzetti, F., Tonelli, G., 2009. A WebGIS for the dissemination of information on historical landslides and floods in Umbria, Italy, Geoinformatica 13,PP. 305-322.

Turner, A., 2006. Introduction to neogeography.

Tulloch, D. L., 2007. Many many maps: empowerment and online participatory mapping. First Monday, 12(2), Available at: cgiwrap/bin/ojs/index.php/fm/article/view/1620/1535.

Yang, C., Raskin, R., Goodchild, M. \& F., Gahegan,2010. Geospatialcyber infrastructure :past, present and future, Computers, Environment, and UrbanSystems, 34(4),PP. 264277. 